\title{
Hyperbranched PbS and PbSe Nanowires and the Effect of Hydrogen Gas on Their Synthesis
}

\author{
Matthew J. Bierman, Y. K. Albert Lau, and Song Jin*
}

Department of Chemistry, University of Wisconsin-Madison, Madison, Wisconsin 53706.

E-mail address: jin@chem.wisc.edu

\section{RECEIVED DATE (to be automatically inserted)}

\section{EDS of PbSe nanowires.}

Energy dispersive x-ray spectroscopy (EDS) was carried out on PbSe nanowires in a Philips CM200 TEM operated at $200 \mathrm{kV}$ to reveal $\mathrm{Pb}: \mathrm{Se}$ in the ratio of 48:51, indicating PbSe within the error of the EDS analysis.

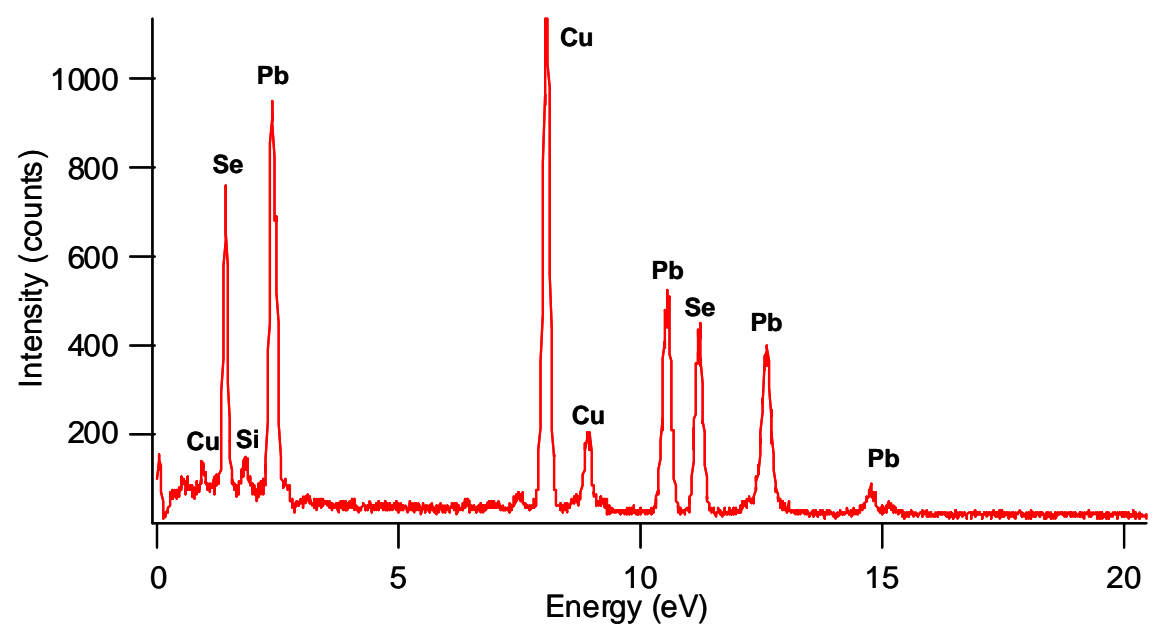

Figure S1. Energy dispersive x-ray spectrum (EDS) of a PbSe nanowire. Copper is present from the sample grid.

\section{$\mathrm{Pb}-\mathrm{S}$ and $\mathrm{Pb}$-Se binary phase diagrams.}

Phase diagrams of $\mathrm{Pb}-\mathrm{S}$ and $\mathrm{Pb}-\mathrm{Se}$ both show that low melting point lead can form eutectics with $\mathrm{PhS} / \mathrm{PbSe}$ and can be thought of as a VLS catalyst for the creation of $\mathrm{PbS} / \mathrm{PbSe}$ nanowires. 

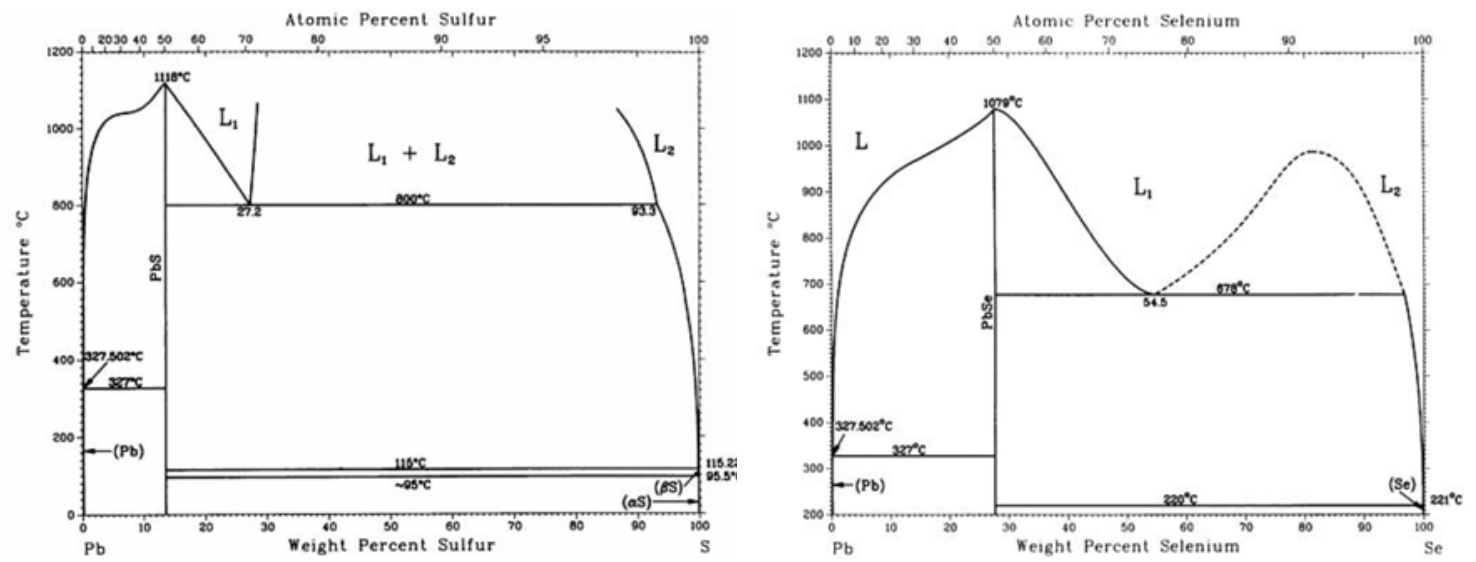

Figure S2. Binary phase diagrams for $\mathrm{Pb}-\mathrm{S}$ and $\mathrm{Pb}-\mathrm{Se}$, take from ASM Handbooks Online; http://products.asminternational.org; Accessed 5/21/2007.

\section{Raman spectroscopy of PbSe nanowires and single crystal.}

Similarly to PbS, Raman spectroscopy of PbSe nanowires was taken on a HORIBA Jobin Yvon LabRAM ARAMIS Confocal Raman Microscope at room temperature. These peaks are likely to be due to photo-oxidation but can not be assigned due to the lack of information on Raman spectroscopy of PbSe materials.

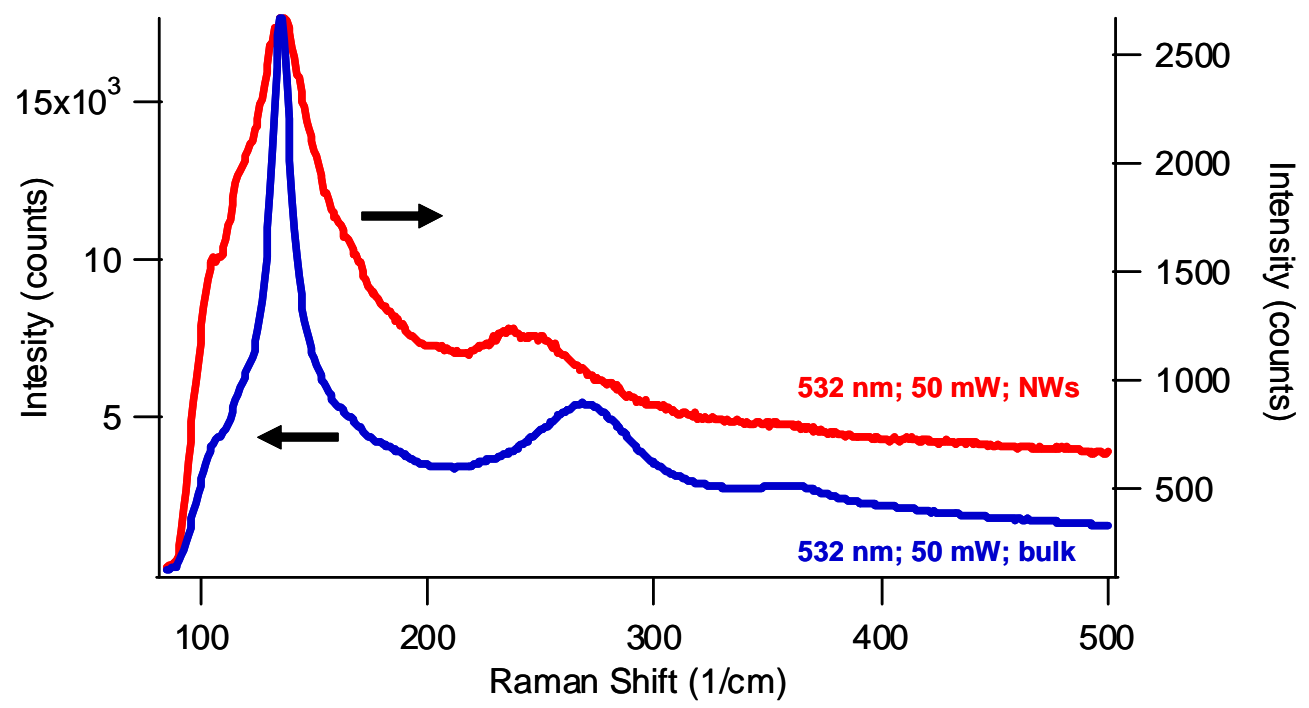

Figure S3. Raman spectroscopy taken on PbSe nanowire cluster in comparison with that of a PbSe single crystal on the (100) crystal face. These features are likely due to mostly photo-oxidation. 